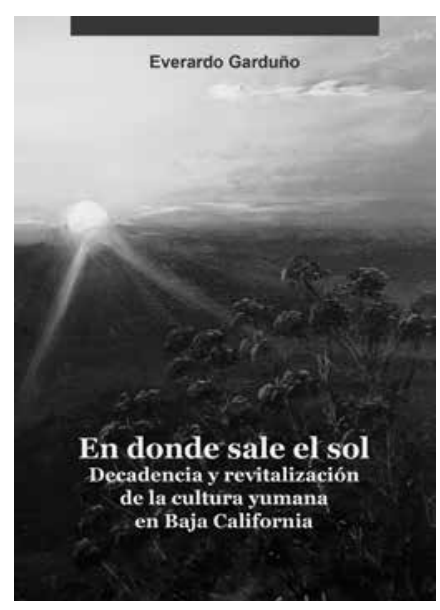

- En donde sale el sol. Decadencia

y revitalización de la cultura yumana

en Baja California

EVERARDo GARDUÑo, 2016

Universidad Autónoma de

Baja California, Mexicali

\title{
El sol sale de nuevo: la revitalización de la cultura yumana
}

\author{
ANDRÉS ANTONIO FÁBREGAS PUIG
}

The Sun Raises Again: The Revitalization of Yumano Culture

Andrés Antonio FÁbregas Puig

Centro de Investigaciones y Estudios Superiores en Antropología Social-Occidente, Guadalajara, Jalisco, México apfgup@gmail.com

Desacatos 57 ,

mayo-agosto 2018, pp. 198-202 a Península de Baja California sigue siendo hoy el recipiente de inmigraciones que llegan de todos los rincones de México y aún del extranjero. Vista desde el otero del Estado nacional mexicano, Baja California es tierra de frontera, es decir, de expansión del propio Estado, a la manera en que Frederick Jackson Turner lo planteó en su texto titulado "El significado de la frontera en la historia americana" (1987). Aunado a esta característica, está el hecho de que la antropología, mejor dicho, los profesionales de esa disciplina formados en México, tardaron años en fijar sus ojos en el Norte mexicano - que en realidad son varios Nortes-, obsesionados con el análisis de Mesoamérica, por una parte, y por la otra, como resultado de las políticas de asimilación instrumentadas durante varias décadas del siglo Xx bajo el rubro de "indigenismo", que trató a las poblaciones indias del país con el mismo rasero mesoamericano. La concentración de la enseñanza de la antropología en la Ciudad de México, donde se ubica la Escuela Nacional de Antropología e Historia (ENAH), apoyó el centralismo en la 
investigación, no sólo en la etnología o la antropología social, también en la arqueología, la lingüística, la antropología física y la etnología. En un contexto así, es de celebrarse que un etnólogo como Everardo Garduño insista en la relevancia que tiene, tanto para las teorías antropológicas como para la comprensión del país, el análisis de las poblaciones y las culturas de Baja California. Ello, a su vez, remite a considerar la importancia que ha tenido y tiene la Universidad Autónoma de Baja California (UABC) en el impulso a las ciencias sociales en general y a la antropología en particular. Destaca también la presencia del Instituto Nacional de Antropología e Historia (INAH), cuyos investigadores han contribuido al avance de la arqueología en la región.

El libro de Everardo Garduño, En donde sale el sol..., está organizado en textos temáticos más que en capítulos propiamente dichos. A estos textos les precede una introducción, mientras que las consideraciones finales sellan el libro. Además, contiene un apartado sobre los informantes, la bibliografía y el índice. En total, 283 páginas con sabor a trabajo de campo, a largas caminatas antropológicas por los senderos de la variedad cultural y de la percepción del medio ambiente en el que se desarrolla la vida de los pueblos estudiados.

Los grupos humanos que se analizan en el libro pertenecen a la familia etnolingüística yumana: cucapá, kiliwa, pa-ipai, kumiai y tipai. Son pueblos del gran conjunto de las "gentes del Norte", como dicen las antiguas crónicas, de los pueblos nombrados chichimecas, que habitaron la Huey Chichimecatlalpan, como decían los informantes de fray Bernardino de Sahagún.

Estos pueblos tuvieron sus primeros contactos con los europeos hacia el siglo XVII. En ese momento, como era característico de los pueblos de la Gran Chichimeca, los yumanos practicaban una economía aleatoria propia del nomadismo. Desde la "Introducción”, Garduño señala que la transición de un estilo de vida como ése a la sedentarización ocurrió en tres ciclos, en el lapso que va del siglo XVII hasta mediados del Xx, al relacionarse primero con soldados, exploradores y misioneros — siglo XVII-, después con mineros y vaqueros estadounidenses, concesionarios de tierras en la Baja California durante el siglo XIX, y por último, con los campesinos sin tierra que fueron acomodados en la Baja California a mediados del siglo Xx. Este largo proceso significó cambios drásticos en la vida y cultura de los pueblos yumanos, lo que orilló a quienes analizaban estos pueblos a pensar que estaban en un proceso de asimilación, o lo que es lo mismo, de extinción cultural. Es una perspectiva que el propio Garduño compartió. Por esa razón, sus primeros textos sobre estos pueblos se titularon En donde se mete el sol... (Garduño, 1994). Ahora es diferente: el etnólogo localizó un proceso de revitalización cultural, que responde mejor al concepto de transculturación que al de aculturación. Por ello, la nueva perspectiva es En donde sale el sol..., el rumbo que ahora toma la reflexión contenida en su libro, en el que destaca la propuesta, congruente con lo anterior, de que la situación actual de los yumanos es resultado de tres procesos: el periodo misional o establecimiento del régimen colonial, la expansión capitalista en el siglo XIX — que lleva el sello del extractivismo, sobre todo en actividades mineras-y la Revolución mexicana en los comienzos del siglo XX.

A la luz de trabajos como En donde sale el sol..., cabe revisar las discusiones entre Fernando Ortiz, protoantropólogo cubano, autor de Contrapunteo cubano del tabaco y el azúcar (1983); Bronislaw Malinowski (1983), antropólogo británico, y Gonzalo Aguirre Beltrán (1946), teórico mexicano del indigenismo asimilacionista. En el contexto de esa discusión, Fernando Ortiz, apoyado por Malinowski, opuso el concepto de transculturación al de aculturación defendido y desarrollado por Aguirre Beltrán. En la revisión de esa discusión, deben incluirse los entornos de los que provienen ambos conceptos. En el caso de los yumanos, es 
importante incorporar rasgos culturales que provienen de la vida ranchera, de los criadores de ganado, de los vaqueros. Asimismo, habría que discutir qué rasgos de los yumanos fueron intercambiados y son susceptibles de ser localizados entre los rancheros. La revitalización cultural incluye el idioma, su valoración y su uso cotidiano, además de las nuevas estrategias ecológico-culturales que elaboran los yumanos actuales. A lo largo de su libro, Garduño expone los rasgos de la vida social y cultural que permiten hablar de un renacimiento cultural de los pueblos yumanos y de la dinámica del proceso. En este contexto, me parece que debe subrayarse la importancia del parentesco como eje de la organización social de pueblos como los yumanos y el proceso del criterio organizacional basado en esas relaciones, dados los cambios originados con la imposición del régimen colonial y sus resultados actuales. En el libro hay material etnográfico interesante para establecer una discusión como la que sugiero.

Me llama la atención la manera en que la antropología visual destaca en la experiencia del autor en su trabajo con los yumanos. Esta parte de la narración expone la necesidad de la confección de un video para comprender rasgos culturales y mecanismos sociales contemporáneos que caracterizan no sólo a los yumanos sino su entorno relacional. Es decir, no se trata de un "registro de imágenes" o de un apoyo a la etnografía, sino de un recurso de método - la antropología visual—, que permite estudiar aspectos de la vida de un pueblo que de otra manera quedarían ocultos a la observación, por lo tanto, a la reflexión. Garduño es quizá uno de los antropólogos mexicanos con más experiencia en este campo, lo que provoca la tentación de instarlo a que escriba una suerte de texto metodológico sobre el quehacer etnográfico a partir de la antropología visual.

Otro aspecto que también sobresale es la alta capacidad de los yumanos para elaborar ecologías culturales en ambientes muy diversos. Me parece que eso se compagina con la variedad idiomática que, a su vez, señala el hecho de la desaparición de cientos de lenguas a raíz del establecimiento del régimen colonial. Con todo, la revitalización cultural emerge como resultado no sólo de la energía de un pueblo sino de su vocación de sobrevivir y otorgar continuidad a sus peculiaridades culturales. En este sentido, encuentro que es básica la reflexión teórica sobre procesos que arrancan en el colonialismo para llegar a nuestros días, protagonizados por pueblos como el yumano, ejemplo de una larga inserción en los procesos de globalidad desatados por la expansión de Europa occidental y la difusión e imposición del capitalismo y la modernidad en el planeta. La etnografía contemporánea, como demuestra Garduño, es una puerta de entrada para reconstruir, con base en la etnohistoria, la vida de pueblos como los que se estudian en este libro y teorizar desde allí los caminos de la resistencia contracolonial, sus resultados y las perspectivas que se desprenden de ahí.

La mención de la dinámica demográfica es otro factor de interés en la reflexión general sobre los yumanos. En 1937, el destacado demógrafo Sherburne Cook calculó una población de 10000 personas. En la actualidad, sobreviven 1000 personas autoidentificadas como rieños y serreños. En el grupo de los rieños están los cucapá, que habitan en El Mayor Indígena Cucapá. Los serreños son los kumiai de Juntas de Nejí, San José Tecate, Peña Blanca y San José de la Zorra, y los kiliwa del ejido de Quiliguas -Arroyo de León-, que son los grupos objeto de la etnografía y de la reflexión del libro.

Mientras avanzaba en la lectura de En donde sale el sol... emergieron historias de fronteras, desde las de naturaleza ecológico-cultural y lingüísticas hasta las políticas. Es más, la foto de la página 60 me llamó la atención justo sobre esta historia de fronteras: es el Cerro de Cuchumá, icónico para los kumiai, cuya geografía se divide por las verjas fronterizas entre México y Estados Unidos. Es decir, la foto sugiere un tema complejo relacionado con la emergencia del norte de México y el suroeste de 
Estados Unidos que conllevó la división territorial de la Gran Chichimeca y la consolidación de una frontera internacional que influye en la percepción etnológica de nuestros días. Es un conjunto de problemas que, me parece, la antropología contemporánea no puede eludir. Más todavía, la foto evoca la continuidad de un proceso de transculturación cuyas dinámicas contemporáneas es preciso explicar para entender los ámbitos que los propios Estados nacionales crean y cómo afrontan ese hecho los pueblos divididos por las fronteras, que deben transformarlas en espacios de convivencia.

Como lo apunté, este libro es una historia de cómo se crean las fronteras, cómo son de naturaleza diversa y cómo cada una configura un aspecto para la antropología de nuestros días. Por ejemplo, un tema que en apariencia no tiene nada que ver con los argumentos centrales del trabajo de Garduño, la presencia de Ricardo Flores Magón en Baja California, conduce a pensar en las concepciones de los grupos radicales de la Revolución mexicana acerca del destino de pueblos como el yumano en el contexto de la imaginada nación mexicana. Más aún, conduce a la reflexión de los encuentros y desencuentros entre las transformaciones de México y las percepciones de la sociedad estadounidense sobre ellas. Como ejemplo, cito el reciente libro de Claudio Lomnitz (2016). Es un tema que mueve a reflexionar los encuentros y desencuentros entre los pueblos nómadas, las "gentes del Norte" y la Revolución mexicana, aspecto que Garduño señala en la página 67. Hay raíces culturales de por medio en esos procesos que nos llevan a pensar en las equivocaciones del indigenismo, que operó con los modelos mesoamericanos de organización social en mente, sin conceder que los pueblos de la Gran Chichimeca poseen una historia propia con todo lo que ello significa. Es justo mencionar que nuestro finado y querido colega Juan Luis Sariego se preocupó por este aspecto y lo trató con amplitud. Son temas que no escapan a la pluma de Everardo Garduño.
Otro elemento destacado es el acercamiento a las culturas ganaderas, que se desprenden del periodo colonial, y a personajes sociales y culturales, como el vaquero. La influencia de las "películas del Oeste" generó la percepción buscada de que en la raíz de la nación estadounidense están los pioneros, los vaqueros del Oeste, con sus armas, ese culto a las armas que aún no termina y que tantas desgracias le trae a ese país. En donde sale el sol... desmiente la imagen del vaquero como personaje exclusivo del correr de la frontera en Estados Unidos y muestra que "la cultura del vaquero" subió desde el sur hacia el norte, como lo demuestra también la configuración histórica de los Altos de Jalisco. Una pregunta dentro del ámbito del concepto de transculturación es: ¿qué rasgos yumanos porta la cultura del vaquero en Baja California? En ese mismo ámbito cabe señalar que la articulación entre yumanos y otros sectores de la población sigue siendo realidad por medio del conflicto, como antaño sucedió entre nómadas y sedentarios, entre ganaderos y yumanos. Aquí adquiere importancia el propio concepto de conflicto y su estudio, como el momento en que la transculturación opera con intensidad y muestra las partes de sus propios mecanismos organizacionales y sus capacidades de transponer rasgos culturales.

La transculturación religiosa es otro tema tratado por Garduño, que debe incluirse como un factor de relevancia para entender los procesos de revitalización cultural. A ello se asocia - por lo menos así lo leo- la reinvención de las identidades de la lucha por la tierra y el recuerdo de que el origen de la disciplina de la etnohistoria está en la lucha de los indios de Norteamérica por sus territorios.

La frontera se borra, aunque allí está. Se diluye en un renacimiento cultural resultado de la emigración. En este proceso, la mujer es el centro de la revitalización cultural. Como lo dice Garduño, la mujer es el personaje yumano que más evidencia la diferencia cultural, al portar la sabiduría 
ancestral de la herbolaria, la cerámica, la cestería, además de ser la interlocutora entre la sociedad y el Estado. Aquí hay un campo de reflexión que está a la espera.

Después de leer En donde sale el sol..., concuerdo con Everardo Garduño: "en conclusión, los yumanos de Baja California son grupos vigentes. De tradición nómada, cazadora y recolectora, los cucapá, los kiliwa, los pa-ipai, kumiai, tipai e incluso los cochimíes, contradicen puntualmente las apocalípticas versiones sobre su extinción y asimilación cultural” (p. 272).

El trabajo de Garduño demuestra que ha salido un nuevo sol, hecho al tamaño de la vitalidad de la cultura yumana, como dice uno de los mitos de la creación, que transcribo:
No sirve, dijo Komat, y silencioso, sin decir palabra comenzó a moldear con sus manos otro sol, su propio sol, dando por resultado un hermoso sol radiante, enorme y caliente que levantó otra vez con sus dos manos, y haciendo un gran esfuerzo lo lanzó hacia los cielos, hacia el Este, para que desde entonces aquel robusto astro luminoso iniciara su eterno y cotidiano viaje del oriente a occidente (p. 121).

En donde sale el sol... es la narración de cómo una cultura renace, vuelve al mundo renovada y enriquece a un país diverso, como México. Gracias a Everardo Garduño por este libro que estimula la investigación antropológica y sitúa al noroeste de México como un importante protagonista del nuevo sol que alumbra nuestra disciplina. D

\section{Bibliografía}

Aguirre Beltrán, Gonzalo, 1946, La población negra de México 1519-1810. Estudio etnohistórico, Ediciones Fuente Cultural, México.

Garduño, Everardo, 1994, En donde se mete el sol. Historia y situación actual de los indígenas montañeses de Baja California, Consejo Nacional para la Cultura y las Artes, México.

Lomnitz, Claudio, 2016, El regreso del camarada Ricardo Flores Magón, Era, México.

Malinowski, Bronislaw, 1983 [1940], "Introducción”, en Fernando Ortiz, Contrapunteo cubano del tabaco y el azúcar, Editorial de Ciencias Sociales, La Habana, pp. 123-133.

Ortiz, Fernando, 1983 [1940], Contrapunteo cubano del tabaco y el azúcar, Editorial de Ciencias Sociales, La Habana.

Turner, Frederick Jackson, 1987, “El significado de la frontera en la historia americana”, en Secuencia, núm. 7, pp. 187-207. 